\title{
THE IMPACT OF SELECTED FACTORS OF UTILITY MOTOR VEHICLES OPERATION CONDITIONS ON THE ECONOMY DRIVING
}

Article analyzes the specific conditions of operating commercial vehicles and deals with their influence on the operation economy of a selected vehicle category. The article results are the empirically determined factors of the selected conditions that have the strongest (greatest) influence on variability of the average fuel consumption of selected vehicles. These factors are also supported by appropriate calculations. The next part of the article is creating a regression model through which it is possible to measure the impact of the factor changes on an observed variable.

Keywords: Operational conditions of road vehicles, average fuel consumption, telematics information systems in transport, correlation, regression.

\section{Introduction}

Within the research and development of intelligent transport systems there is an effort to determine individual groups of factors which affect the final price of transport output the most and which could create complete calculating formula for dynamic illustration of expenses for necessary transport. In this article we focus on specific group of external factors which create surrounding of the vehicle and distinctively affect consumption of fuel within utility vehicles. The aim was to methodically define field of these factors from total volume with documented narrowest connection on operation efficiency of selected utility vehicles and price of transport output.

\section{Definition of used means and methods}

Expenses on fuel present more than a third of expenses per kilometer and the importance of this item within cost structure of transport companies will be still more significant. Within monitoring of variable costs the largest attention is dedicated especially to them. Transport companies as well as producers of traffic engineering are seeking for constant solutions leading to reduction of fuel consumption and therefore given partial results of research in the area of possible factors on the price of transporter performance are trying to offer new look on these problems.

After agreement with individual experts from cooperating transport companies, we set range of 8 primary criteria from the previous 36 available where we assumed the strongest connection with operation fuel consumption. For further research of their influence on monitored quantity there were chosen 2 approaches. First called empirical-expert approach (AHP method) determined which of the individual criteria has the largest relative importance on the compared consumption within monitored goods vehicles of the selected category. Second exact approach using methods of mathematical statistics (correlation and regression analysis), measured power of connection among entered variables (selected criteria) in comparison to fuel consumption variable.

\subsection{Characteristics of monitored file unit}

In order to fulfill target of research, we focused on extraction of required data from vehicle control units, within particular sample. We also used possibilities of telematic applications MAN TeleMatics and OptiFleet. Access passwords were provided by PROCAR a.s. (joint-stock company) and AVEmoto s.r.o. (limited by shares). From the point of statistic file observance there were assured comparable atmospheric-climatic conditions as well as

\footnotetext{
* Lukas Holesa, Karol Hrudkay

University Science Park of the University of Zilina, University of Zilina, Slovakia

E-mail: holesal@azet.sk
} 
the same technical parameters of the selected vehicles. These were parameters connected with:

- average gross train weight,

- vehicle category,

- vehicle model,

- axles,

- curb weight of the serviceable vehicle,

- capacity weight.

\subsection{Description of selected way of observance and obtaining of factors (parameters) within vehicle operation}

Current specific solutions of world producers of articulated vehicles enable analysis of selected conditions within vehicle operation during fulfilling of shipping tasks, with provable effect on drive efficiency. According to information outputs of control units, it is possible to monitor and analyze conditions of vehicle operation, as illustrated in the following picture - Fig. 1.

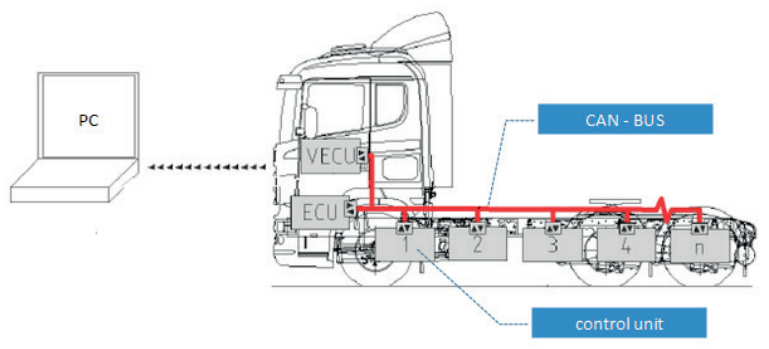

Fig. 1 Transfer data from control units to PC with the appropriate software of the system Source: Prepared by the author on the basis

of the information society as PROCAR and AVEmoto Ltd.

Through MAN TeleMatics and OptiFleet applications it is possible to examine individual statements of vehicle operation (aggregate statement, time statement, statement on fuel consumption, statement of surrounding conditions, statement of recorded data and so on), which are part of company fleet. Microsoft Office Excel is the most suitable way of extraction of the individual parameters of operation in xls format what was enabled only by OptiFleet, whereas using the MAN TeleMatics the necessary data had to be transcribed manually.

\subsection{Determination of data files with key parameters of operation on selected sample of vehicles}

Information was derived from company fleets and under the conditions described in more details in 1.1 and 1.2 chapters. Specifically it was concerned with 80 vehicles driving on various routes. Following converted statistic operations, file was reduced to 72 items. Reason of the reduction were some bad numerical values recorded by control unit in certain time intervals of drive. From aggregate statements of vehicles, there were completely exported 42 parameters of operation.

From the point of data inaccessibility to the character of roadway we took into account only parameter of construction condition of roadways, specific altitude profile which is characterized by macro profile of concerned passage of roadway. In order to express average vertical distance and average longitudinal slope of passages within selected routes there were used MapSource 6.13.5 and Map\&Guide. Both these software applications are map software which can draw high-altitude profile of route on correspondent base map. Monitored vehicles moved in countries like Slovakia, Czech Republic, Hungary, Austria, Germany, countries of Benelux, and the UK. Values of an average slope within routes were among $\langle 0.2 \quad 4\rangle$ and vertical distance among <-1.3 1>. We can draw a conclusion that it is a slightly undulated territory.

\section{Application of selected mathematical and statistical methods on obtained indices}

\subsection{Multi-criteria analysis}

From all obtained parameters mentioned in 1.3 subhead, selection we worked with was further reduced to 8 key parameters (see Table 1). Selection has been made following the consultations with competent staff (working with given issues) from cooperating companies. In order to express significance of selected criteria on fuel consumption, one of the most suitable methods seemed to be AHP method.

Evaluation criteria for the establishment of matrix

Table 1

\begin{tabular}{|l|l|}
\hline K1 & service break distance \\
\hline K2 & engine brake distance \\
\hline K3 & average driving speed \\
\hline K4 & optimal speed range \\
\hline K5 & average gross train weight \\
\hline K6 & consuption with CC \\
\hline K7 & overrun (proportion of driven distance) \\
\hline K8 & accelerator position \\
\hline
\end{tabular}

Source: Author

The basis of this method was to record subjectively selected values of significances, which were compared among alternatives for decision matrix. Experts ( 5 persons) kept at disposal so called descriptors in order to determine preference among compared criteria. Descriptors serve for graduation of significance between each pair of criteria, in case of equal criteria one point is used [1, 2, 3 and 4] and a problem of the same significance is eliminated. 


\begin{tabular}{|c|c|c|c|c|}
\hline & criterion & product elements & ninth root of product & the final weight criteria \\
\hline 1. & K1 & 0.0037125 & 0.571434748862014 & 0.0607599932490068 \\
\hline 2. & K2 & 4.1184 & 1.15205404339426 & 0.122496568573273 \\
\hline 3. & K3 & 20.9454545454545 & 1.3555295172092 & 0.144131879411394 \\
\hline 4. & K4 & 2166.666666666667 & 2.15565477372526 & 0.229208268764845 \\
\hline 5. & K5 & 2692.30769230769 & 2.20298971307321 & 0.23424133789645 \\
\hline 6. & K6 & 0.00005580357142857 & 0.375548645092112 & 0.0399316513143662 \\
\hline 7. & K7 & 0.0404040404040404 & 0.725508457751585 & 0.0771424717920476 \\
\hline 8. & K8 & 0.237416904083571 & 0.866066347660978 & 0.0920878289986174 \\
\hline & & $\Sigma=$ & 9.40478624676862 & 1 \\
\hline
\end{tabular}

Source: Author

Due to the limitation of article scope, in the following part there will be provided only a table with calculated respective significance weights of the individual criteria (see Table 2).

From the provided review of criteria determination it is clear that the highest priority was assigned to $\mathrm{K} 5, \mathrm{~K} 4$ and $\mathrm{K} 3$ criteria and the lowest to $\mathrm{K} 6$ criterion. The outputs were taken into account in further processes and solutions.

\subsection{Partial correlation analysis}

Question analysis will serve to consider strength of connection (correlation) among pairs of variables, or one value from the other values [5] from $n$ monitored values (criteria) $X_{1}, X_{2} \ldots$ $\mathrm{Xn}$ (see Table 1). Firstly, we used multiple correlation in order to find out significances of the individual criteria (variables) on one monitored value of average operation fuel consumption (dependent variable). As in the previous chapter, object of correlation are at the moment only values of parameters obtained from control units (8 criteria from AHP method) [6].

This correlation deals with correlating of one value with other measured values. After unsatisfactory results a partial correlation has been worked out in order to find out so called clear correlation of 2 values eliminating impact of other measured values (other criteria). We used SAS Learning edition 4.1 and Minitab 16.1.0 software for creating correlation matrix and correlograms. In the following pictures (see Figs. 2 - 9) you can see outputs of partial correlation of 8 selected criteria towards monitored value of consumption. As well as in case of multiple correlation we used SAS software.

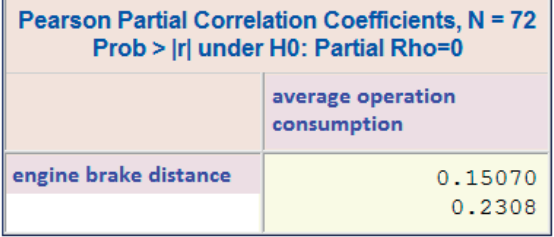

Fig. 2 Partial correlation no. 1 - engine brake distance

\begin{tabular}{|l|r|}
\hline \multicolumn{2}{|c|}{$\begin{array}{c}\text { Pearson Partial Correlation Coefficients, } N=72 \\
\text { Prob }>|r| \text { under H0: Partial Rho=0 }\end{array}$} \\
\hline & $\begin{array}{l}\text { average operation } \\
\text { consumption }\end{array}$ \\
\hline service break distance & $\begin{array}{r}-0.00456 \\
0.9713\end{array}$ \\
\hline
\end{tabular}

Fig. 3 partial correlation no. 2 - service break distance

Pearson Partial Correlation Coefficients, $\mathrm{N}=72$ Prob > |r| under H0: Partial Rho=0

average operation consumption

\begin{tabular}{|r|r}
\hline overrun (proportion of driven & 0.26318 \\
0.0342
\end{tabular}

Fig. 4 partial correlation no. 3 - overrun

Pearson Partial Correlation Coefficients, $\mathrm{N}=72$ Prob $>|r|$ under H0: Partial Rho $=0$

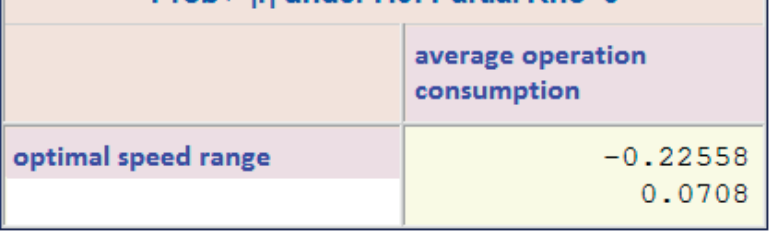

Fig. 5 Partial correlation no. 4 - optimal speed range 


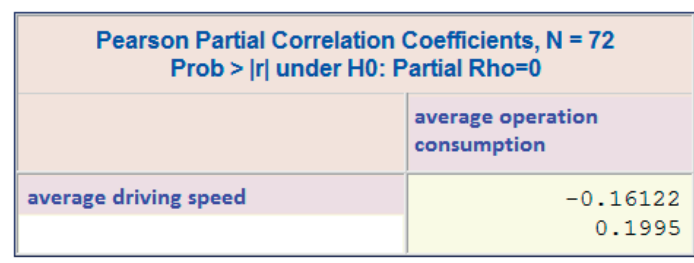

Fig. 6 Partial correlation no. 5 - average driving speed

\begin{tabular}{|l|l|}
\hline \multicolumn{2}{|c|}{$\begin{array}{c}\text { Pearson Partial Correlation Coefficients, } N=72 \\
\text { Prob }>|r| \text { under H0: Partial Rho=0 }\end{array}$} \\
& $\begin{array}{l}\text { average operation } \\
\text { consumption }\end{array}$ \\
\hline consumption with CC & $\begin{array}{r}-0.16536 \\
0.1880\end{array}$ \\
\hline
\end{tabular}

Fig. 7 Partial correlation no. 6 - consumption with CC

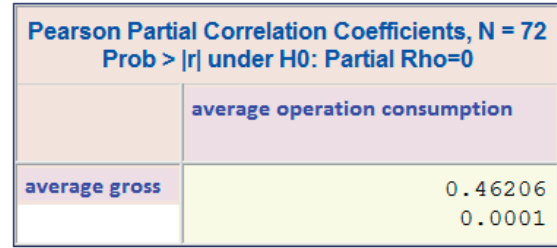

Fig. 8 Partial correlation no. 7 - average gross

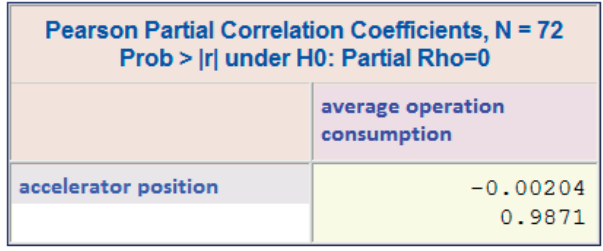

Fig. 9 Partial correlation no. 8 - accelerator position

Individual figures show respective partial empirical correlation coefficients (always the first value in the second column) determined again by point estimates, this time obtained pursuant to the relation 1 . It is theoretically assumed with this type of correlation as compared to the previous (multiple) one that $\mathrm{Y}$ and $\mathrm{Z}$ are some random variables and $\left(\mathrm{X}_{1}, \mathrm{X}_{2}, \ldots \mathrm{X}_{\mathrm{p}}\right)$ is their vector. The partial correlation coefficient gives here the correlation rate of variables $\mathrm{Y}, \mathrm{Z}$ with exclusion of the vector effect $\left(X_{1}, X_{2}, \ldots X \rho\right)$. Further assuming that $\left(\mathrm{y}_{1}, \mathrm{z}_{1}, \mathrm{x}_{11}, \mathrm{x}_{21}, \ldots, \mathrm{X}_{\rho 1}\right)$, $\left(\mathrm{y}_{2}, \mathrm{z}_{2}, \mathrm{x}_{12}, \mathrm{x}_{22}, \ldots, \mathrm{x}_{\rho 2}\right), \ldots,\left(\mathrm{y}_{\mathrm{n}}, \mathrm{z}_{\mathrm{n}}, \mathrm{x}_{1 \mathrm{n}}, \mathrm{x}_{2 \mathrm{n}}, \ldots, \mathrm{x}_{\rho \mathrm{n}}\right)$ is random selection of range $\mathrm{n} \mathrm{z}(\rho+2)$ - of random dimensional vector $\left(\mathrm{Y}, \mathrm{Z}, \mathrm{X}_{\mathrm{l}}, \ldots\right.$, $\mathrm{X}_{\rho}$ ), that $\mathrm{R}$ is empirical correlation matrix of the random vector $\left(\mathrm{X}_{1}, \mathrm{X}_{2}, \ldots \mathrm{X}_{\rho}\right)$ and that $\mathrm{r}_{\mathrm{YX}}$ is correlation coefficient of variables $\mathrm{Y}$, $X_{i}(i=1,2, \ldots, \rho)$, then $r_{z X}$ is empirical correlation coefficient of variables $Z, X_{i}(i=1,2, \ldots \rho)$. We should further mark line vectors of empirical correlation coefficients $R(Y, X)=\left(r_{y x 1}, r_{y x 2}, \ldots, r_{y x p}\right)$, $R(Z, X)=\left(r_{z x 1}, r_{z x 2}, \ldots, r_{z x p}\right)$ and their column vectors $R(X, Y)=\left(r_{y x 1}\right.$, $\left.r_{y x 2}, \ldots, r_{y x p}\right), R(X, Z)=\left(r_{z x 1}, r_{z x 2}, \ldots, r_{z x p}\right)$, where then $r_{y z}$ is empirical correlation coefficient of variables $\mathrm{Y}, \mathrm{Z}$ (see the relation 1).

The second value in the second column represents statistical significance of each criterion ( $P$ - value). Same as with multiple correlation, on the grounds of the selected level of significance $(\alpha=0.05)$ those parameters that meet the condition, or can significantly near the selected level of significance, respectively, can be considered statistically significant $(P-$ value $\langle\alpha)$.

Criteria service braking, motor speed range and full load condition (see Figs. 3, 5 and 8) can be considered statistically significant. Compared to the multiple correlation the statistical significance of criteria narrowed from five to three particular criteria. The criterion motor speed range can be to a certain extent arguable, as it remained in the zone of negative correlation $\left(r_{Y, Z / X}=-0.22558\right)$ and moves very closely around the selected level of significance (P-value $=0.0708$ ), which is, however, according to [3] still acceptable. As there is a certain linearity of data and acceptable significance achieved, this criterion can be included in the short model of selected criteria. Said negative correlation can be caused by the fact that the percentage share of zone of optimal speed in which the vehicle remained within the whole passed route, was taken into account.

As the good result of the selected correlation we can regard also the fact that coverage of the mentioned criteria has been found out (service break distance, optimal speed range, average gross train weight) within AHP method, where these criteria were assigned a significant importance weight and results of the partial correlation. With the AHP method, said criteria achieved relatively important significance weights, namely criteria such as optimal speed range $(0.2292)$ and average gross train weight (0.2342), representing the highest assigned weights, and the criterion service break distance achieved the value (0.0607) what can be interpreted as not the lowest value reached among the compared criteria (see Table 2). The important thing is that all these three criteria among all 8 criteria within partial correlation appeared as the only statistically significant on the selected $\alpha$ level and reach the closest dependence (relation) with monitored variable (operation consumption) what is proven by their correlation indices (service break distance $=r_{Y, Z / X}=0.26318$, average gross train weight $=r_{Y, Z / X}=0.46206$ and optimal speed range $=r_{Y, Z / X}=|0.22558|$ ) (see Figs. 3, 5 and 8).

$r_{Y, Z I X}=\frac{r_{x z}-R(Y, X) \cdot R^{-1} \cdot R(X, Z)}{\sqrt{\left(1-R(Y, X) \cdot R^{-1} \cdot R(X, Z)\right) \cdot\left(1-R(Z, X) \cdot R^{-1} \cdot R(X, Z)\right)}}$ 


\section{Creating of multi-criteria linear regression model according to parameter significances}

Only those criteria which reached statistical significance at the selected level of significance such as service break distance, optimal speed range (optimal speed range zone) and average gross train weight (see. partials covariance) were incorporated into the said model. We used Minitab software to create this model (see Table 3).

The output of the software for criteria

Table 3

\begin{tabular}{|c|c|c|c|}
\hline model parameters & values & $\begin{array}{c}\text { error of the mean } \\
\text { value }\end{array}$ & Prob>1 T I \\
\hline limits & 23.112 & 1.442 & 0.001 \\
\hline par 1 & 0.12993 & 0.04464 & 0.005 \\
\hline par 2 & -0.10406 & 0.01991 & 0.001 \\
\hline par 3 & 0.4466 & 0.07372 & 0.001 \\
\hline \multicolumn{4}{|c|}{76.3} \\
\hline$R^{2}[\%]$ &
\end{tabular}

Relevant model describes approximately 76.3 percent of variability of used data as it is apparent from the value of coefficient of determination. We have not included model with all expert specified criteria (parameters) into the article since it is not relevant from the general point of view. When creating it, we proceeded in a similar way as in regression model. Assumption that after dropping statistically insignificant parameters a coefficient of determination will increase, turned up to be the right one. In outputs where the model included all 8 criteria, it was only at the level $R^{2}=0.49$. Statistical significance of the individual regression coefficients (second column Table 3) reflects statistical significance reached within partial correlation of three concerned criteria. It is necessary to mention significant improvement of parameter 2 (optimal speed range) from 0.071 (values reached at regression analysis with all 8 criteria) to 0.001 (see fourth column in Table 3 - P-value). Such process of model creating is generally favorable because of its simple economic interpretation as well as simpler procedures when statistically estimating parameters and testing statistical significance.

According to this output from software (see Table 3), it is possible to construct required regression model containing only three primary key criteria (see relation 2). According to [7, 8 and 9], if value of $\mathrm{R}^{2}$ is not below 0.7, given model has not only theoretical meaning but it is also applicable in practice. It is possible to apply within a range of defined parameter values (criteria - operational and road) the created model where a 95 per cent confidence interval was used,

$y_{P S}=23.112+0.12993 x_{1 t}-0.10406 x_{2 t}+0.44660 x_{3 t}$

Through this model it is possible to empirically compare how value decrease or increase of some parameters affects the monitored variable. Change of any value has to be within the range of values used for creating of corresponding regression model.

The following relations demonstratively show how the average operation fuel consumption would be changed if average gross train weight increased by 50 per cent in comparison to the former one under the same conditions of other operation parameters as well as routes grade. We can assume from values on route no. 2 , which is one of the routes where measured operation data were exported from the vehicle control unit.

$y_{P S}=23.112+0.610671-5.400714+$

$+8.932=27.30 \mathrm{l} / 100 \mathrm{~km}$

$y_{P S}=23.112+0.610671-5.400714+$

$+13.398=31.10 \mathrm{l} / 100 \mathrm{~km}$

In relation 3 the former values of all three parameters are used and the result differs compared to the real fuel consumption $(27.10 \mathrm{l} / 100 \mathrm{~km})$ by 0.20 liter which is deviation of only around $0.73 \%$. In relation 4 the value of average gross train weight increased from $10 \mathrm{t}$ to $30 \mathrm{t}$ with remaining conditions constant. As it is apparent from the given relationship, with such change operation fuel consumption would increase to $31.101 / 100 \mathrm{~km}$ what represents an increase by around 4.4 liter, so 12.86 per cent. In a similar way we can even empirically present the effect of other 2 parameters (criteria), how a monitored quantity would change at their nominal increase or decrease. The values of all three criteria may be changed but only in a specified range for routes undertaken on flat or slightly undulating territory.

According to the results from calculations, it is possible to say that ridden routes were only on slightly undulating territory (routes going through countries of Central and Western Europe). Therefore we assumed that available parameters of altitude profiles of routes will have an important effect (binding) on monitored fuel consumption what was confirmed when making partial correlation and subsequent attempt to stop the model with particular parameters. From this reason, the appropriate model is not mentioned in the article.

\section{Conclusion}

According to the results from both selected approaches, we discovered "overlap" of significances in three specific criteria from which a particular model has been built in the mentioned subhead. These are operation factors (criteria) which according to calculated and nominal proven outcomes can be assessed as the factors with the largest effect on operation fuel consumption of vehicles (among all other obtained factors). This influence of selected factors may be also numerically expressed by the said model. The particular model reached average 0.22 per cent deviation among extrapolated and real values of average operation 


\section{COMMNICOIIIONS}

fuel consumption within selected sample of vehicles. According to subjective opinion of authors as well as opinion of addressed experts (evaluators within AHP method), it is possible to say that this deviation is from the theoretical point of view and also for the carrier himself at acceptable (minimum) level.

In the article we managed to define a small group of external factors proved to have the largest effect on monitored quantity. These factors belong to the whole group of factors which can enter into price for hauling performance.

\section{Acknowledgement}

This paper is supported by the following project: University Science Park of the University of Zilina (ITMS: 26220220184) supported by the Research\&Development Operational Program funded by the European Regional Development Fund.

\section{References}

[1] KALCEVOVA, J.: Study Materials - Multi-criteria Analysis (in Czech), [elektronicky zdroj], [cit. 2015-02-23], 2008, http://jana.kalcev. cz/vyuka/kestazeni/EKO422-KriterialniMatice.pdf.

[2] FIALA, P. at al.: Multi-Criteria Decision Making, VSE : Praha, 1994, ISBN 80-70709-748-7.

[3] SAATY TH. L., VARGAS L. G., WENDELL R. E.: Assessing Attribute Weights by Rations. Omega, Intern. J. of Management Science, vol. 2, No. 1, pp. 9-13, 1983, Priority Setting in Complex Problems. In: Hansen, P.: Essays and Surveys on Multiple Criteria Decision Making. Proc. of the Fifth Intern. Conference on Multiple Criteria Decision Making, Berlin/Heidelberg/NewYork : Springer-Verlag, pp. 326-336, 1983., Axiomatic Foundation of the Analytic Hierarchy Process in Management Science, 32, No. 7, pp. 841-847, 1986.

[4] TRIANTAPHYLloU, E.: Multi-Criteria Decision Making: A Comparative Study. Dordrecht : Kluwer Academic Publishers, 2000, ISBN 0-7923-6607-7.

[5] MARKECHOVA, D., STECHLIKOVA. B., TRPAKOVA, A.: Statistical Methods and their Applications (in Slovak), Nitra : UKF, 2011, 515 p., ISBN 978-80-8094-807- 8.

[6] STOPKA, O., KAMPF, R., KOLAR, J., KUBASAKOVA, I.: Identification of Appropriate Methods for Allocation Tasks of Logistics Objects in a Certain Area, Our Sea, Intern. J. of Maritime Science \& Technology, vol. 61, No. 1-2, 2014, ISSN: 0469-6255.

[7] CHAJDIAK, J.: Statistics Simply - $1^{\text {st }}$ ed. (in Slovak), Bratislava : STATIS, 2003, 196 p., ISBN 80-85659-28-X.

[8] STOPKA, O., KAMPF, R., KOLAR, J., KUBASAKOVA, I., SAVAGE, CH.: Draft Guidelines for the Allocation of Public Logistics Centres of International Importance, Communications - Scientific Letters of the University of Zilina, vol. 16 (2), 2014, pp. 14-19, ISSN: $1335-4205$

[9] STOPKA, O., KAMPF, R. Draft Methodology for Selecting the Appropriate Storage Area Design in Intermodal Logistics Center, Applied Mechanics and Materials, vol. 708, 2014, Chapter 5. pp 300-305. ISSN 1662-7482. 